\title{
Desafios das práticas arqueológicas e da preservação: dinâmicas socioculturais sobre e nos entornos dos sítios arqueológicos na Amazônia
}

\section{Challenges of archaeological practices and preservation: sociocultural dynamics on and around archaeological sites in the Amazon}

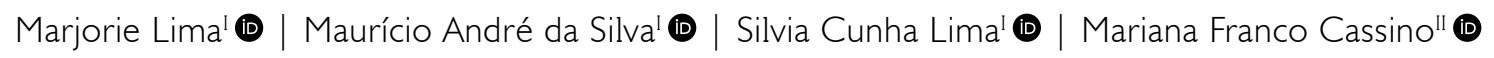 \\ Eduardo Tamanaha ${ }^{\text {III }}$ \\ Universidade de São Paulo. Museu de Arqueologia e Etnologia. São Paulo, São Paulo, Brasil \\ "Instituto Nacional de Pesquisas da Amazônia. Manaus, Amazonas, Brasil \\ IIIInstituto de Desenvolvimento Sustentável Mamirauá. Tefé, Amazonas, Brasil
}

\begin{abstract}
Resumo: As relações das pessoas com as coisas e os sítios arqueológicos no contexto amazônico é extremamente plural e contextual. A cada comunidade, pesquisadores e pesquisadoras aprendem outras formas de pensar as intrínsecas relações entre passado e presente. $\bigcirc$ Laboratório de Arqueologia do Instituto de Desenvolvimento Sustentável Mamirauá tem primado por uma atuação interdisciplinar para o desenvolvimento de ações e pesquisas com as comunidades ribeirinhas nas áreas de proteção. Neste artigo, abordamos as práticas arqueológicas e a salvaguarda do patrimônio em contextos comunitários. Por meio da arqueologia, da conservação arqueológica e da educação, refletimos sobre nosso papel como profissionais que atuam a partir de diferentes saberes e grupos de interesse, onde valores, significados e resultados são revisitados a todo momento em que novas colaborações são estabelecidas, seja entre pesquisas acadêmicas, seja entre agentes da comunidade. Para isso, discute-se os trabalhos desenvolvidos em Boa Esperança, localizada na Reserva de Desenvolvimento Sustentável (RDS) Amanã, que recebe arqueólogos e arqueólogas desde 2006. Consideramos que a pesquisa se transformou pelo contexto comunitário e pela ampliação do envolvimento de diferentes agentes, reorientando nossas ações em busca de alternativas de médio e longo prazo para a gestão colaborativa e sustentável do patrimônio arqueológico amazônico.
\end{abstract}

Palavras-chave: Arqueologia amazônica. Patrimônio arqueológico. Preservação arqueológica. Lago Amanã. Comunidade ribeirinha. Unidade de conservação.

Abstract: People's relationships with things and with archaeological sites in the Amazonian context are extremely plural and contextual. In each community, researchers learn other ways of thinking about the intrinsic relationships between the past and present. The Mamirauá Institute's Archaeology Laboratory has excelled at an interdisciplinary approach to developing activities and research together with riverine communities in protected areas. In this article, we discuss archaeological practices and the challenges of preserving archaeological heritage in community contexts. Through archaeology, archaeological conservation, and education, we reflect on our role as professionals working from different knowledge and interest groups, where values, meanings, and results are revisited every time new collaborations are established (whether these involve academic research or community agents). To do so, we examine the work carried out in the Boa Esperança community, located in the Amanã Sustainable Development Reserve, which has been receiving archaeologists since 2006. This research is considered to have been transformed by the community context and by broader engagement with different agents, reorienting efforts to find medium- and long-term alternatives for collaborative and sustainable management of the Amazon's archaeological heritage.

Keywords: Amazonian archaeology. Archaeological heritage. Archaeological preservation. Amanã Lake. Riverine community. Protected area.

Lima, M., Silva, M. A., Lima, S. C., Cassino, M. F., \& Tamanaha, E. (2021). Desafios das práticas arqueológicas e da preservação: dinâmicas socioculturais sobre e nos entornos dos sítios arqueológicos na Amazônia. Boletim do Museu Paraense Emílio Goeldi. Ciências Humanas, 16(2), e20190153. doi: 10.1590/2178-2547-BGOELDI-2019-0153

Autora para correspondência: Marjorie Lima. Universidade de São Paulo. Museu de Arqueologia e Etnologia. Av. Professor Almeida Prado, 1466 - Cidade Universitária. São Paulo, SP, Brasil. CEP 05508-070 (limanmarjorie@gmail.com).

Recebido em 07/01/2020

Aprovado em 17/11/2020

Responsabilidade editorial: Jorge Eremites de Oliveira
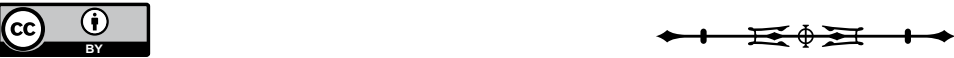


\section{INTRODUÇÃO}

Nas últimas décadas, a prática arqueológica tem sido povoada por muitas coletividades e diferentes agentes têm contribuído com a renovação da área. Diversificados grupos e suas histórias particulares, vivências, territorialidades, relações com o mundo material e imaterial, entre outras instâncias, têm posto desafios para o desenvolvimento de uma ciência engajada, com diferentes dilemas no século XXI (F. Silva, 2014; Liebmann \& Rizvi, 2008; Colwell-Chanthaphonh et al., 2010; Cabral, 2014). O nosso ato, como especialistas, na transformação de lugares em sítios arqueológicos e de coisas em patrimônio, tem cada vez mais incorporado a preocupação de como essas ações reverberam nas populações do presente. No contexto amazônico, onde geralmente sítios arqueológicos estão em terras indígenas, comunidades ribeirinhas, quilombolas, entre outros povos tradicionais, a arqueologia tem o desafio de desenvolver práticas sensíveis, que promovam a empatia com as pessoas do presente e que tenham desdobramentos sociais.

Diferentes pesquisadoras e pesquisadores vêm se debruçando sobre a relação entre os coletivos humanos, comunidades locais e bens arqueológicos voltados aos desafios amazônicos (Bezerra, 2011, 2017, 2018; Cabral, 2014; Cabral et al., 2018; Carneiro, 2009; Costa Leite, 2014; L. G. Ferreira \& Bezerra, 2013; Gomes, 2016; H. Lima et al., 2013; H. Lima, 2019; Machado, 2013, 2014; Pereira, 2019; Rocha et al., 2014; F. Silva, 2013, 2014; F. Silva \& S. Lima, 2015; F. Silva et al., 2011). Embora com um leque abrangente de casos, e a partir de diferentes propostas de análise, os trabalhos convergem para um olhar plural sobre aquilo que definimos como patrimônio, onde a relevância e a compreensão de seus papéis na vida cotidiana compõem parte de sua permanência e, consequentemente, de sua sustentabilidade.

Na Reserva de Desenvolvimento Sustentável (RDS) Amanã, uma unidade de conservação localizada entre o médio rio Solimões e o baixo rio Japurá, foram identificados, até o momento, mais de 50 sítios arqueológicos (Figura 1), que apresentam configurações e contextos distintos e que estão distribuídos nas comunidades, localidades de moradores isolados, roçados e áreas desocupadas ( $M$. Lima, 2018; S. Lima, 2018). Destes, Boa Esperança é o mais estudado (B. Costa, 2012; B. Costa et al., 2012; Gomes, 2015, 2016; M. Lima, 2018; S. Lima, 2018; M. Silva, 2019). A pesquisa arqueológica sistemática na região começou a ser desenvolvida em 2006, com o principal objetivo de identificação de sítios arqueológicos para futura elaboração de um plano de manejo do patrimônio arqueológico. Isso é oriundo da possibilidade de degradação dos vestígios arqueológicos ${ }^{1}$, em especial vasilhas afloradas na superfície das comunidades, e do desejo de moradores e moradoras quanto à criação de um programa de turismo ecológico de base comunitária.

Desde então, atividades de levantamento, escavação, conservação e um diagnóstico para a elaboração de um programa de educação patrimonial foram desenvolvidos (B. Costa, 2012; Gomes, 2015; Gomes et al., 2014). Neste contexto, por meio da colaboração de diferentes instituições, pesquisas têm sido realizadas no sentido de contribuir para a compreensão dos processos de longa duração local, das paisagens significativas, das relações entre pessoas e plantas e da preservação do material arqueológico exposto às intempéries, entre outras discussões (Cassino et al., 2018; Furquim, 2014; M. Lima, 2018; S. Lima, 2018; Gomes, 2015; M. Silva, 2019, entre outros).

Neste artigo, propomos uma reflexão a respeito dos desafios da pesquisa arqueológica e da gestão do patrimônio material em contextos comunitários, encontrados ao longo dos anos em Amanã. Pressupomos que tal reflexão é um constante movimento, como uma rede de embalar - tão comum nos cenários amazônicos -, e por isso a usamos como metáfora na forma de

\footnotetext{
1 Nota enviada ao Instituto do Patrimônio Histórico e Artístico Nacional de Manaus em 2001, por Glenn Shepard, então pesquisador do Museu Paraense Emílio Goeldi, que relatava a existência e a degradação do sítio arqueológico sob a comunidade Boa Esperança (Shepard, 2001).
}

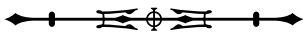




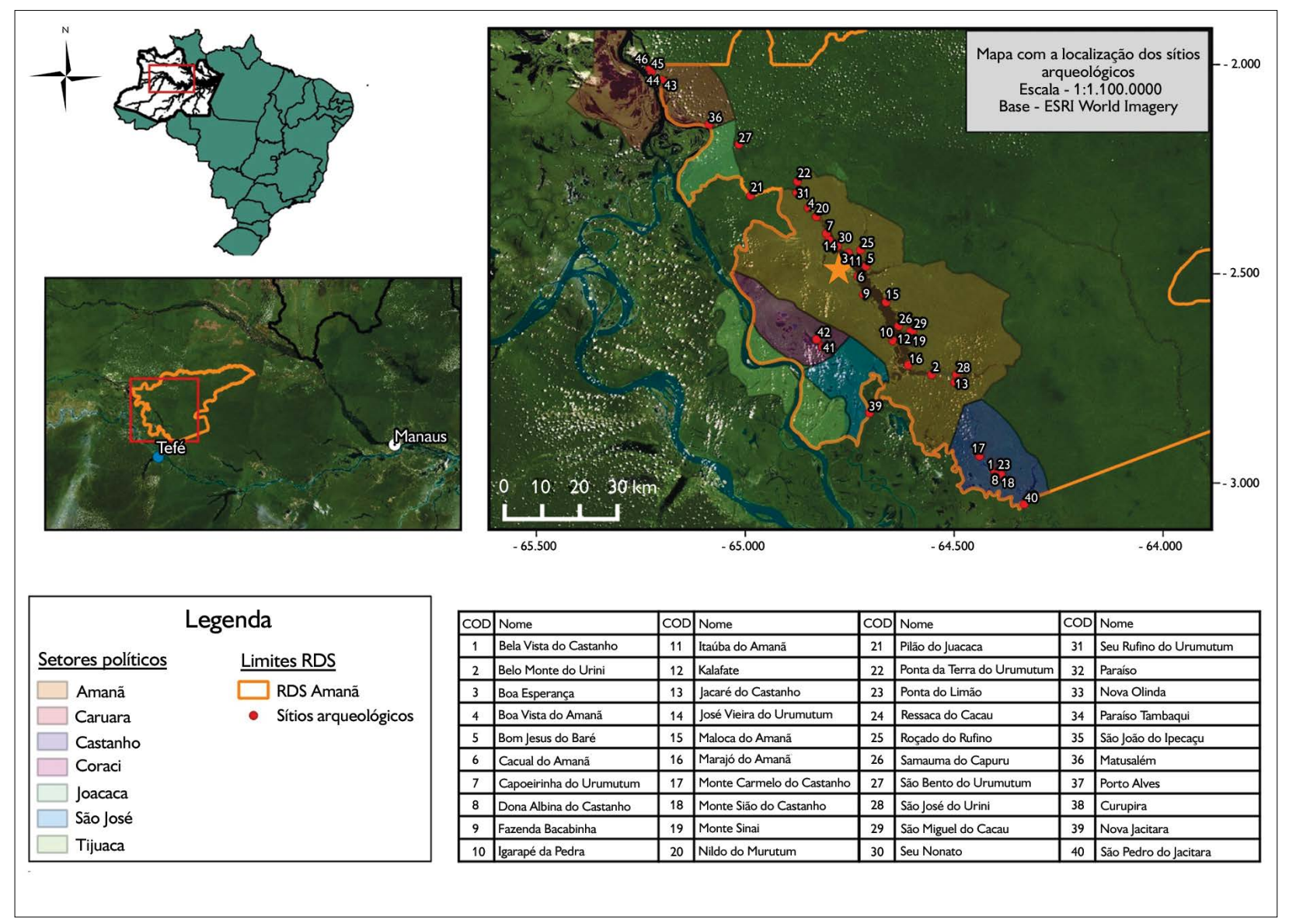

Figura 1. Mapa com a localização dos sítios arqueológicos no lago Amanã, com destaque para o sítio Boa Esperança. Mapa: Eduardo Tamanaha. Edição: Márjorie Lima (2019).

estruturar essa discussão. Para isso, partiremos da 'tessitura da rede', onde construímos um cenário de pesquisas. Em seguida, com o intuito de dialogar com diferentes abordagens, 'atamos a rede' em dois momentos. Em ambos, buscamos mostrar como a interação entre pesquisadores e pesquisadoras - a partir de diferentes abordagens - e moradores e moradoras tem sido benéfica para o desenvolvimento de novas perspectivas sobre as formas convencionais de compreensão e preservação do patrimônio arqueológico local. Finalmente, fazemos um balanço, apontando considerações para o desenvolvimento de ações a médio-longo prazo que surgiram no contexto das pesquisas em Amanã.

\section{TESSITURA DA REDE: CONTEXTO DAS PESQUISAS}

A RDS Amanã é uma unidade de conservação de uso sustentável, que voga pela permanência e manutenção de modos locais e tradicionais de vida, criada através do Decreto Estadual n. 19.021 (1998), que delimitou seu território em uma área abrangendo mais de 2 milhões de hectares, entre o médio rio Solimões e o baixo rio Japurá, sendo o lago Amanã seu principal curso d'água.

Desde a passagem de Alfred Métraux pela região, em 1930, são conhecidos remanescentes funerários no entorno da cidade de Tefé (Hilbert, 1962). Henry Feriz, etnólogo alemão, mencionava a existência de campos

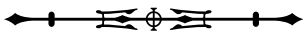


de urnas no lago Amanã 'parcialmente visíveis', com seus 'círculos no chão', no entorno das casas atuais viradas de cabeça para baixo (Feriz, 1963, pp. 148-150) (Figura 2). Tal descrição já denotava uma particularidade dos sítios arqueológicos de Amanã, observada anos mais tarde com o desenvolvimento das pesquisas, que evidenciaram ocorrência de afloramentos de recipientes cerâmicos de grandes dimensões em quintais, terreiros e roçados (B. Costa, 2012; B. Costa et al., 2012).

A pesquisa arqueológica realizada pelo IDSM, com diferentes níveis de colaboração, tem resultado na identificação de diferentes sítios arqueológicos no lago Amanã e adjacências, o que, por sua vez, consolida na região uma abordagem definida como 'levantamento consultante' (Rocha et al., 2014). Trata-se de prática muito comum na arqueologia da Amazônia que se baseia no reconhecimento, pelos moradores e moradoras atuais, dos lugares com vestígios arqueológicos.

Boa Esperança se insere nesse contexto e é atualmente a maior comunidade da RDS Amanã (Figura 3). Segundo Nascimento (2020, p. 103), a comunidade é formada por aproximadamente 300 pessoas. Sua criação remonta a três décadas, e as primeiras famílias que ocuparam a área vieram do Juá Grande, um igarapé mais acima, no lago. Suas gentes são descendentes de migrantes nordestinos de segunda e terceira geração, especialmente do Ceará, que escolheram essa ponta de terra por ser elevada e boa para o plantio.

Boa Esperança também é o maior sítio arqueológico, sendo o mais longamente ocupado dentro da reserva, de acordo com os dados disponíveis. Curiosamente, passado e presente compartilham grandes densidades populacionais nesse lugar. Trata-se de um sítio a céu aberto, localizado na margem direita do lago Amanã, que foi mapeado, escavado e monitorado entre 2006 e 2019. A área do sítio possui mais de 22 hectares, mas somente na área central ocorre grande concentração de fragmentos cerâmicos com até um metro de profundidade e a presença de terra preta. Ao longo de mais de 3.000 mil anos de ocupação,

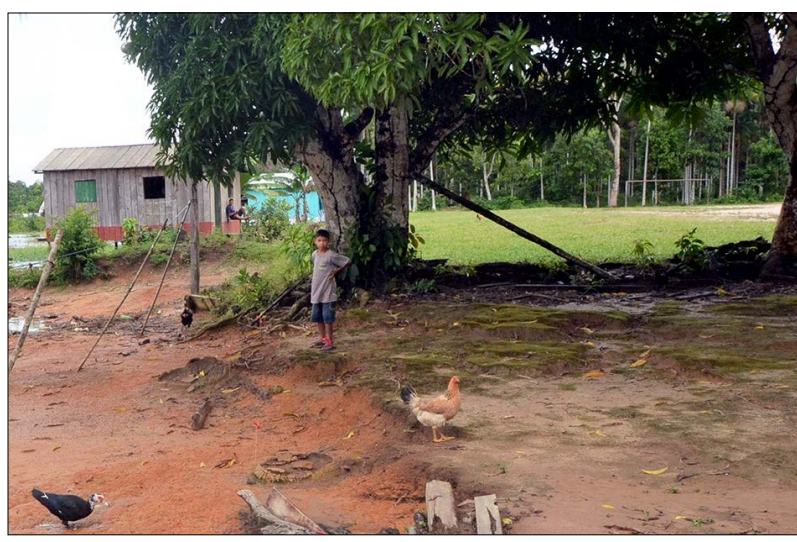

Figura 2. Visita da equipe do Instituto de Desenvolvimento Sustentável Mamirauá (IDSM), realizada em 2013, e registro do afloramento de vasilhas no piso da comunidade. Foto: Laura Furquim (2013).

Boa Esperança teve áreas demarcadas por diferentes usos. Atualmente, há mais de 100 vasilhas aflorando em superfície.

Estima-se que a maioria dessas vasilhas esteja associada à chamada fase Caiambé, da Tradição Borda Incisa, fase definida por Hilbert (1968) e posteriormente estudada por Gomes (2015), que tem cronologia de ocupação entre 1.600 a 1.100 anos atrás, período que tem sido interpretado como um momento de regionalização nessa porção da Amazônia. Cabe destacar que fragmentos da mesma fase Caiambé são corriqueiramente coletados e guardados pelas crianças desde longa data, devido aos seus detalhes figurativos, que remetem a bichos e seres da floresta. Atualmente, parte desse material está acondicionada na rádio comunitária Voz da Selva (B. Costa, 2012; M. Silva, 2019), para ser mobilizada e mostrada para visitantes de fora (Figura 4).

Se a partir de 2006 começamos a levantar tais contextos e suas possibilidades de trabalho, e a prática de resgate das vasilhas afloradas era uma entre outras ações realizadas com o intuito de preservação do patrimônio arqueológico, ao longo dos anos essas práticas têm se transformado, e isso abarca desde a mudança dos objetivos iniciais de pesquisas, quando se vai a campo, até a forma de olhar os vestígios e suas relações com as pessoas

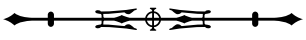




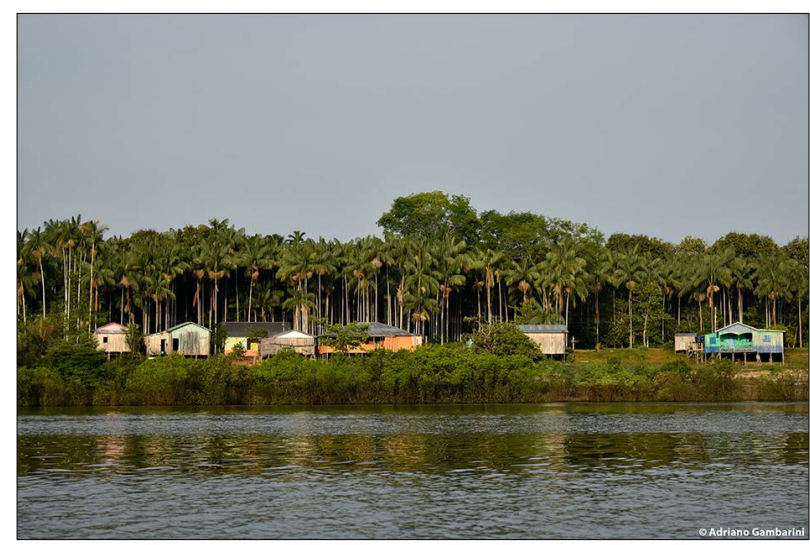

Figura 3. Vista geral da comunidade Boa Esperança, lago Amanã, agosto de 2017. Foto: Adriano Gambarini (2017).

em nosso entorno. Nesse sentido, se insere o esforço de tornar esse trabalho coletivo, fomentado por diferentes abordagens, para que se construam futuramente práticas com perspectivas mais colaborativas.

\section{ATAR A REDE - PARTE I: DIFERENTES OLHARES SOBRE PATRIMÔNIO, LEGADOS E CONTINUIDADE}

As comunidades da RDS Amanã estão organizadas em um modelo no qual a estrutura comunitária é centrada na figura de uma liderança, responsável por representar os interesses das comunidades frente às deliberações coletivas (D. Lima, 1997, p. 302). Geralmente, essas organizações comunais se dão a partir de laços de parentesco, afinidade e compadrio (Peralta, 2013), entretanto as relações podem ser assimétricas, o que é identificado por D. Lima (1997, p. 303) como "disputas entre parentelas distintas"; quanto maiores os núcleos comunitários, maiores as discordâncias e os jogos de poder entre seus participantes. Entre as comunidades, esses conflitos são intensificados e complexificados. Uma das principais implicações disso para as práticas arqueológicas conduzidas nos últimos anos é que tais relações devem ser levadas em consideração na escolha de locais onde serão desenvolvidos trabalhos de maior ou menor duração, uma vez que a pesquisa arqueológica em determinadas áreas passou a ser vista como mais um recurso a ser manejado pelas comunidades.

Nesse sentido, em 2017², durante a retomada das pesquisas na região após quatro anos de nossa ausência enquanto arqueólogas e arqueólogos, percorremos por dez dias diferentes comunidades do lago Amanã, já identificadas como sítios arqueológicos, para relatar resultados de pesquisas anteriores, ouvir e definir estratégias para a realização da etapa de escavação, particularmente em Boa Esperança. Naquela ocasião, a principal demanda para as intervenções em Boa Esperança era a de que ações contemplassem o sítio como um todo, expandindo-se para além do centro da comunidade, onde até então haviam se concentrado as áreas de escavação. Em razão disso, procuramos estabelecer áreas de intervenção pequenas, mas dispersas ao longo da comunidade, que contemplassem os interesses das pesquisas e da própria comunidade, abrangendo quintais, áreas sociais comuns facilmente acessadas por todas e todos (como as proximidades do centro comunitário) e áreas de capoeira. A todo momento, nos deparamos

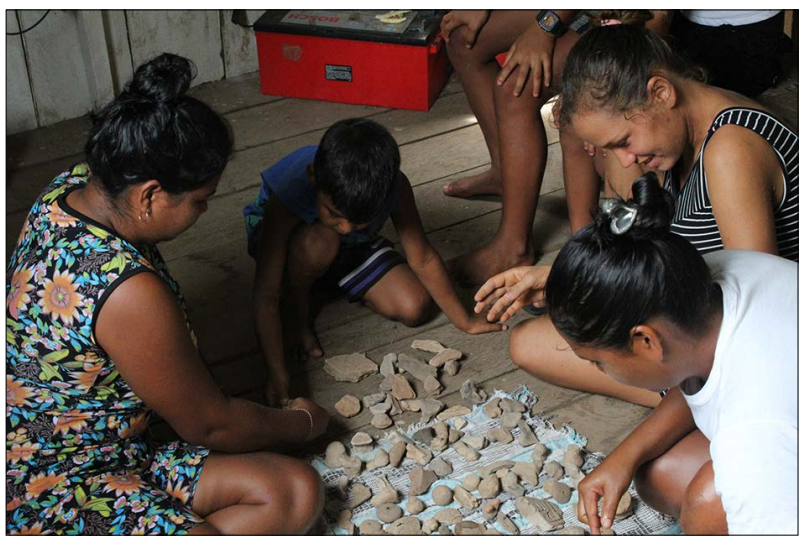

Figura 4. Moradoras da comunidade Boa Esperança observam a coleção arqueológica da rádio Voz da Selva, com suas crianças. Foto: Maurício André (2019).

\footnotetext{
2 Trabalhos conduzidos através do processo do Instituto do Patrimônio Histórico e Artístico Nacional (IPHAN) n. 01490.001350/2017-38,
} intitulado "Arqueologia nas unidades de conservação do médio rio Solimões" (2017).

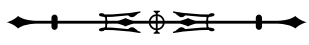


com a importância da escolha de determinadas áreas para escavação, tanto do ponto de vista da pesquisa em si, como das relações sociais que tais locais ativam, seja por estarem em áreas de trânsito intenso - e isso permite que mais pessoas participem ativamente do processo de escavação -, seja por estarem no quintal de alguém socialmente isolado da comunidade. Observamos, com isso, que todas as escolhas de uma prática arqueológica têm um peso a ser considerado para a vida cotidiana daquele lugar posteriormente.

Além de influenciarem a escolha das áreas amostradas, as percepções locais sobre os legados das populações do passado têm o poder de somar novos elementos à teia que conecta passado e presente. Tais elementos podem colocar em questão os limites dos territórios que guardam as marcas de antigas ocupações humanas e as relações de alteridade que as pessoas vivas constroem a respeito daquelas que habitaram e transformaram o lugar onde vivem. Em Amanã, além dos potes visíveis na superfície, da terra preta arqueológica e dos cacos dos índios antigos, os moradores e moradoras interpretam, em algumas ocasiões, as paisagens e a vegetação em torno da ocorrência de plantas, como a castanha-de-cutia, a jurubeba e a pimenta, em áreas que não ocorreriam 'naturalmente' como a constatação de presença humana antiga. Em diferentes momentos, essa percepção nos levou a um duplo questionamento: primeiro, quais marcadores de antropização são relevantes em suas visões? E segundo, a partir dessa lógica, poderíamos então rever a definição de sítio arqueológico? Este questionamento não é exclusivo da arqueologia de Amanã (ver Cabral, 2016, p. 85).

A pesquisa arqueobotânica e ecológica realizada durante a ação de $2017^{3}$ abriu caminhos para um olhar mais abrangente, construído em conjunto entre pesquisadores e pesquisadoras e as pessoas locais, sobre o patrimônio arqueológico do sítio Boa Esperança.
Ao apresentarmos os carvões escavados como coisas arqueológicas, que possuem o potencial de informar sobre como as pessoas do passado se alimentavam, cultivavam e manejavam plantas e paisagens, encontramos um canal de interlocução prolíico. Se, por um lado, como qualquer cultura naturalmente dinâmica, muitos dos hábitos das populações pré-coloniais não são compartilhados pelas populações locais atuais, por outro, as espécies vegetais identificadas no registro arqueológico do sítio Boa Esperança continuam ocorrendo, sendo utilizadas, apreciadas, manejadas e apropriadas pelas populações do presente.

Em uma sociedade onde os limites entre natureza e cultura são fluidos ou inexistentes (Descola, 2016), é coerente pensar que o patrimônio natural é também cultural. Sob esse olhar, as roças, os quintais, os açaizais, as capoeiras, as áreas de mata se juntam aos vasilhames que afloram próximo às casas, ao tornarem-se também um elo com os povos do passado. De fato, como discutido por Machado (2009), um dos mais importantes indicadores de continuidades entre passado e presente nas sociedades amazônicas encontra-se na maneira particular como essas sociedades se relacionam com o ambiente.

Esta visão contribuiu para chamar nossa atenção para o fato de que as paisagens cotidianas são carregadas de temporalidade e memória, sendo as plantas parte da paisagem construída, mas também parte da vida da comunidade. A partir disso, vemos que incorporar tais paisagens à discussão sobre herança, alteridade e reconhecimento pode ser um caminho frutífero para o planejamento de ações conjuntas de conservação de um patrimônio que, para além de seu valor simbólico, é também prático e funcional.

As experiências em Amanã nos permitem propor, então, que a pesquisa, a socialização e a gestão do patrimônio são ações que devem ser pensadas conjuntamente entre

3 Durante as escavações de 2017, foram coletados carvões e sedimentos para análise de macro e microvestígios botânicos. Também foram realizados inventários florísticos e mapeamentos participativos, a fim de conhecer a composição florística do sítio arqueológico e a distribuição das concentrações de espécies vegetais úteis nas áreas de uso da comunidade.

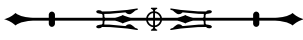


os diversos agentes envolvidos, para que haja uma compreensão abrangente do que é chamado de vestígio arqueológico. Esses vestígios muitas vezes estão vivos, porque engendram relações entre humanos e não humanos, dão significado a diferentes situações, marcam lugares. Ampliar a compreensão plurissemântica dos vestígios arqueológicos e entender como as pessoas leem e interagem com essas materialidades e os espaços nos quais estão - nominados por nós de sítios arqueológicos - são elementos fundamentais para superarmos a noção de que as pessoas não possuem consciência patrimonial. O que está em jogo é uma rede de interações e agentes que imprimem suas marcas no mundo, em um movimento onde se influencia e se deixa influenciar pelos encontros do presente.

Neste contexto, as pesquisas desenvolvidas pelo IDSM em Amanã têm se afastado de uma investigação 'sobre e para' as comunidades envolvidas, para uma arqueologia 'por e com' as comunidades, como colocado por Gomes et al. (2014, p. 395). A partir do projeto coordenado por B. Costa (2012), a pesquisadora Maria Tereza Vieira Parente liderou os trabalhos preconizados pela legislação como educação patrimonial. Como continuidade desse projeto inicial, atualmente, são desenvolvidas ações com professores, professoras e estudantes da Escola Municipal Prof. Christiano Tramontini, por meio de negociações com o exercício colaborativo da tomada de decisões (Figura 5). O trabalho com a escola é uma demanda local antiga, em que buscamos criar espaços de troca de experiências entre diferentes pessoas, como lideranças, artesãs, jovens envolvidas na organização comunitária e pessoas mais velhas. $\bigcirc$ eixo mediador dessas práticas são as histórias de vida de todos e todas, assim como a história do lugar. Também desenvolvemos uma série de entrevistas com diferentes colaboradores e colaboradoras, com o intuito de remarcar a importância do registro e da documentação do tempo presente nas pesquisas arqueológicas, para que isso acompanhe a salvaguarda do patrimônio arqueológico.

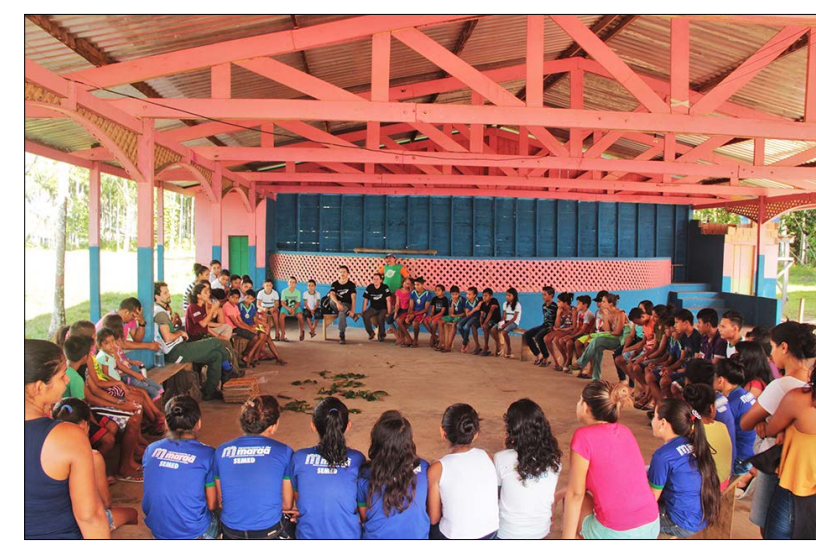

Figura 5. Roda de conversa com professoras e professores, alunas e alunos, realizada no centro comunitário de Boa Esperança. Foto: Caetano Franco (2017).

A forma como esses espaços têm se consolidado busca promover acesso à informação, ao mesmo tempo em que se mantém um campo aberto para que diferentes visões e versões em torno do território local possam dialogar. Essas ações almejam aproximar as pesquisas desenvolvidas dos moradores e moradoras da comunidade, ao passo que se criem fóruns de discussões em torno dos principais problemas enfrentados pelos trabalhos de pesquisa, como a manutenção dos contextos arqueológicos em áreas de grande trânsito das comunidades, a dificuldade da equipe em escavar ou salvaguardar todo o material arqueológico proveniente dos sítios, entre outros. Como trataremos a seguir, diferentes ações de salvaguarda são propostas nessa linha.

\section{ATAR A REDE - PARTE II: VASILHAS QUE AFLORAM - PAISAGENS COM MEMÓRIA OU PATRIMÔNIO EM PERIGO?}

Durante o trabalho de campo, em 2017, enquanto conversávamos com uma das lideranças locais, uma adolescente nos apresentou uma borda de uma vasilha cerâmica que tinha acabado de ser escavada pelas crianças, embaixo de uma moradia. Os atos de nos dar e de mostrar o fragmento poderiam ser, para aquela jovem, uma forma de interação e diálogo conosco. Nós somos as pessoas,

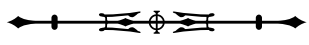


segundo a visão local, que amam essas coisas, os cacos, os alguidare ${ }^{4}$ que afloram pela superfície. Fomos até o local e nos deparamos com um grupo de dez crianças que estavam extremamente curiosas, instigadas pela ação e mobilizadas pelo trabalho da equipe de pesquisadores e pesquisadoras que realizavam algo análogo em seus quintais.

Essa situação nos informa a respeito de nossas práticas e, especialmente, nos coloca reflexivos sobre o poder que possuímos para escavar diferentes localidades do país. Por meio da nossa autoridade cientíica e pelo respaldo do IPHAN, temos a possibilidade legal de pesquisar, escavar, levar as coisas para estudo e salvaguardá-las. Segundo Cabral et al. (2018, p. 261), esse ato pode afastar as pessoas de suas referências culturais e suas formas de contar suas próprias histórias. Nesse sentido, qual a autoridade das comunidades que moram sobre ou próximo aos sítios arqueológicos? Que usos e direitos possuem sobre aquilo que definimos como patrimônio arqueológico? Por que nosso modelo de gestão é entendido como garantia de salvaguarda se, muitas vezes, ignora a importância desses bens para as pessoas que convivem diariamente com eles? Ou, seguindo a mesma lógica, de que preservação estamos falando?

Com esses questionamentos, dois caminhos se abriram: por um lado, por meio de todo o arsenal da prática arqueológica, devemos esclarecer que esse ato é uma ação que deve ser realizada legalmente somente pelos e pelas especialistas, com autorização do IPHAN, e que aquilo é um bem da União. Por outro lado, poderíamos fazer uma autorreflexão: em que medida essa ação fala sobre o impacto de nossa própria presença na vida de diferentes comunidades pelo país? Optamos pelo segundo caminho, norteados pela escuta das diferentes demandas dos moradores e moradoras ao longo de nossa atuação nessa comunidade. Essas situações alargam a nossa prática e demandam novos protocolos compartilhados para a preservação ${ }^{5}$ e fruição dos bens arqueológicos.

Em outra situação, em 2019, um jovem adulto encontrou ao lado de uma casa um pedaço de objeto de cerâmica que estava aflorando. Ele voltou mais tarde, escavou e descobriu uma estatueta, que, segundo a comunidade, representaria o músico Luiz Gonzaga ${ }^{6}$ (Figura 6). Após essa descoberta, o jovem passou a escavar mais áreas à procura de coisas semelhantes, diante de nossa equipe e de toda a comunidade. Ao falarmos que não seria interessante ele fazer isso, pois iria esburacar toda a área, uma criança afirmou: "ele pode escavar sim", reafirmando o pertencimento que essas pessoas têm com o lugar e com os vestígios arqueológicos que os cercam.

Situações como essas tensionam beneficamente nossa atuação profissional com as comunidades. Simultaneamente, abrem a reflexão sobre o compromisso da arqueologia com as dinâmicas da vida local. Quais expectativas geramos quando escavamos em áreas de comunidades? Como nosso discurso sobre os vestígios arqueológicos ressoam para as pessoas que interagem com esses materiais em outras semânticas? Como criar pontes que valorizem

4 Alguidar é uma referência local para os cacos arqueológicos que afloram na superfície da comunidade, associados às coisas dos antigos, coisas que as mães e avós faziam no passado.

5 O termo preservação utilizado aqui abrange um "conjunto de ações” voltadas à "identificação, proteção e gestão do patrimônio" (Sant'Anna, 2015, p. 246). Como também indicado pela autora, embora tenha significado dinâmico, trata-se de um processo de construção que envolve indivíduos e coletivos e, por isso, vai além das atribuições feitas à sua definição pelos Estados nacionais, tendo caráter social. Conservação arqueológica pode ser entendida como um dos desdobramentos neste processo (o de preservação), onde procura ". . . refletir sobre questões teórico-metodológicas específicas na relação dos materiais arqueológicos e seu contexto pré e pós-deposicional" (F. Silva \& S. Lima, 2015, p. 124). Seguindo essa lógica, preservação e conservação arqueológica são, ambas, parte do escopo de gestão do patrimônio.

6 A referência a esse ícone da cultura popular nordestina marca o lugar de origem desses moradores, especialmente cearenses, que migraram para a região em busca de melhorias de vida e para trabalhar nos seringais. Esse diálogo ocorreu em abril de 2019 , na comunidade Boa Esperança, RDS Amanã, no âmbito do desenvolvimento das pesquisas de campo de doutorado de Maurício André da Silva, Mariana Cassino e Rubana Palhares Alves.

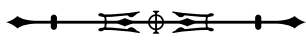




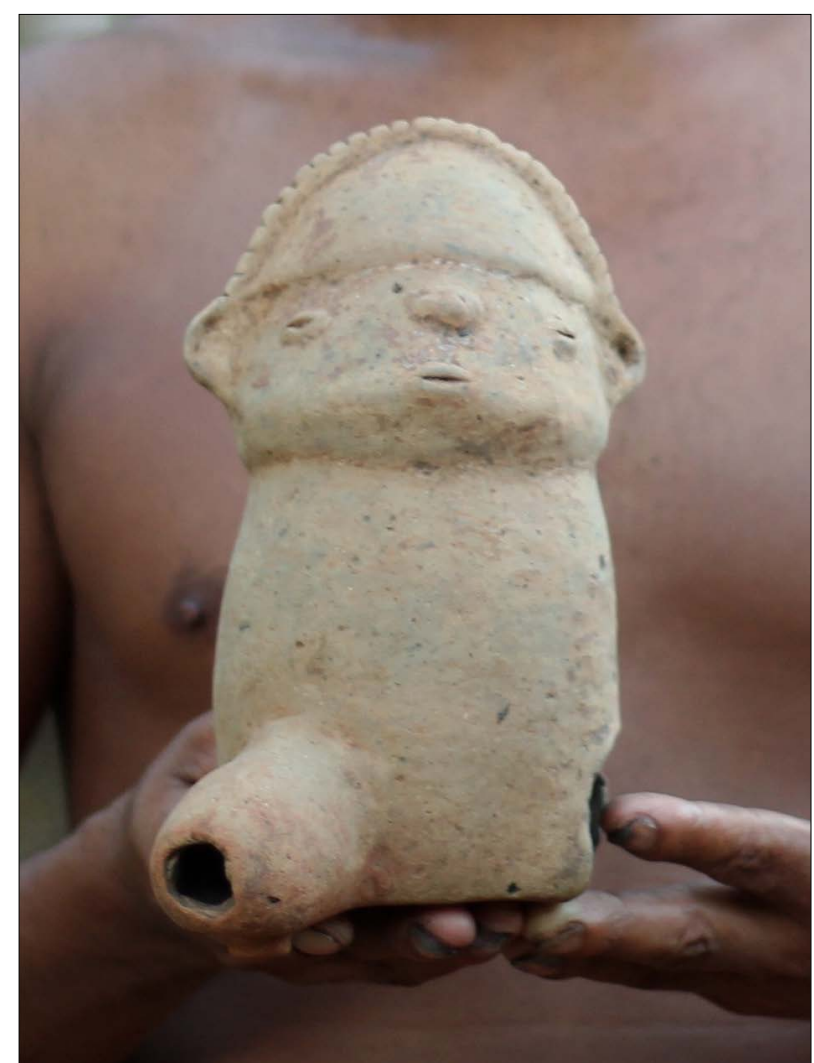

Figura 6. Estatueta encontrada por morador da comunidade Boa Esperança, lago Amanã. Foto: Maurício André da Silva (2019).

os conhecimentos locais e reconheçam o papel da ciência no mundo contemporâneo? Como pensar uma preservação de maneira inclusiva? Embora não seja o intuito aqui responder a todas essas questões, queremos enfatizar que não podemos nos eximir de trazê-las como pontos relevantes ao fazer arqueologia.

Os sítios arqueológicos, antes de serem designados como tal, são espaços de atividades cotidianas das comunidades, terreiros das casas, áreas de roçado, matas do entorno, entre muitos outros. São lugares criados pela dinâmica contemporânea, aspecto que precisa ser refletido pelo campo da gestão do patrimônio arqueológico e, especialmente, pelos desafios da preservação. Perguntamo-nos: no futuro, daqui a 100, 200 anos, essas atividades do presente irão compor outras marcas no registro arqueológico local, aprofundando o tempo de ocupações e usos daquele lugar? Temos percebido, no registro arqueológico de Boa Esperança, indícios de mudanças e continuidades ao longo de 3 mil anos de ocupação. Por que, então, o modo de vida presente não pode ser entendido como mais uma dinâmica na formação e produção do mesmo registro?

No contexto amazônico, perguntas como essas e os desafios em torno da gestão do patrimônio arqueológico em contextos comunitários têm exigido novas posturas e reformulações das práticas científicas, muitas vezes também pautadas por uma reavaliação da legislação, os alcances, potencialidades e limites por ela colocados (Cabral et al., 2018; C. Costa, 2019; L. M. Ferreira, 2013; H. Lima et al., 2017; M. Silva, 2015). Isso se dá devido à presença, ora marcante ora sutil, das "coisas arqueológicas" (cf. Bezerra, 2013 , p. 108) nestes contextos, tornando-se um desafio constante à nossa prática enquanto profissionais em torno do patrimônio cultural.

Dessa forma, especialmente em localidades nas quais as pessoas moram em cima ou próximo de sítios arqueológicos, o que propomos é pensá-los não como algo que se preserva até o presente, mas que continua dentro da dinâmica da vida. Não os podemos encarar somente como uma 'ocorrência do passado', constituindo um resíduo pretérito, valorizado pela arqueologia e mantido dentro dos museus, mas como algo que adquire e continuamente transforma sua significância no presente. Tal perspectiva vem sendo bastante explorada pela gestão e curadoria colaborativa de acervos (Colwell-Chanthaphonh \& Ferguson, 2008; Cury, 2017; Engelstad, 2010; Marçal \& Macedo, 2017; Roca, 2015) ou, ainda, algo próximo de uma 'arqueologia do sensível', uma abordagem que considera como relevantes interações e sentimentos, culminados ou não em ações, das pessoas que lidam diariamente com as coisas do passado, pois tais sentimentos preconizam experiências (Bezerra, 2013; Cabral, 2014; Machado, 2014; H. Lima, 2019).

Em Boa Esperança, Gomes et al. (2014) apontam que os moradores e moradoras reconhecem as vasilhas

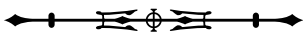


e os fragmentos arqueológicos como coisas dos antigos, vestígios dos indígenas do passado, contrapondo-se à sua ascendência de 'arigós' e 'civilizados'. Veem-se como a quinta geração a ocupar o lugar no qual está Boa Esperança. Concomitante aos fenômenos naturais, como o regime das águas, bem como as ações de animais e de raízes, as pessoas também atuam sobre o registro arqueológico, desafiando a construção de alternativas viáveis para a preservação destes materiais.

Se as vasilhas possuem uma agência no presente, acreditamos que mexer nesse material só é possível com o acordo da comunidade. A própria permanência destas vasilhas ao longo de tantos anos também dá indícios desta relação das pessoas do presente com tais vestígios. É muito comum, quando estamos em Boa Esperança, vermos as pessoas varrendo seus quintais e as áreas com as urnas, ao mesmo passo que a cada chuva e cheia vão acompanhando o afloramento das mesmas, fazendo parte da dinâmica da vida local.

Geralmente, a noção de conservação do registro arqueológico está associada ao resgate e à salvaguarda institucional, pois entende-se que somente com a remoção do material arqueológico do sítio de origem para salvaguarda em uma instituição de pesquisa é possível sua conservação. E essa também tem sido a prática adotada pela equipe do IDSM, em consonância com a legislação vigente. Contudo, nossa experiência tem demonstrado que esta não é a única alternativa para a preservação do patrimônio, seu potencial informacional e simbólico. No mesmo sentido, o estudo arqueológico não é o único a produzir significados a este material. E estratégias de gestão do patrimônio arqueológico (seja in situ ou musealizado), assim como a definição de qualquer ação de conservação ou salvaguarda, devem incorporar uma avaliação de significância desses materiais para as muitas partes interessadas (Avrami et al., 2000; Appelbaum, 2009; Muñoz Viñas, 2005), avaliação que é complexa, pode ser conflituosa entre os diferentes grupos envolvidos e, porque acompanha as dinâmicas socioculturais, precisa ser constantemente repetida (Avrami, 2009, p. 179). Manter e conservar os vestígios arqueológicos in situ pode ser uma estratégia potencial para a sua gestão (Caple, 2016), especialmente para o envolvimento de diferentes comunidades na sua proteção e no seu uso.

Resgatar todos os vasilhames que afloram pela comunidade Boa Esperança também não é viável, devido a uma série de fatores, como falta de recursos, falta de pesquisas cujos objetivos específicos sejam o estudo funerário, falta de espaço para salvaguardá-las e, principalmente, porque tal ação afastaria a comunidade desses referenciais. Como discute Pereira (2019), em muitas localidades da Amazônia, a imagem que a arqueologia deixa é de roubo das peças, pois são levadas para longe, 'escondidas' nas reservas, onde a população em geral não tem acesso. Apesar disso, notamos que a demanda local para que esses vasilhames sejam escavados é crescente, talvez estimulados pela própria pesquisa arqueológica. Ademais, apesar da intensa discussão por parte do IDSM sobre o turismo de base comunitária, atualmente, ainda não há um projeto consolidado que articule o turismo com o patrimônio arqueológico da região.

Com a finalidade de repensar nossa prática no que tange às ações de conservação e de gestão do patrimônio arqueológico, iniciamos, em 20177, a elaboração de uma metodologia de mapeamento e monitoramento in situ dos afloramentos de material arqueológico, realizando documentação fotográfica e coleta de dados, como fração exposta da vasilha, quantidade e dimensão dos fragmentos, descrição da cerâmica e avaliação do estado de conservação. Utilizando como base um mapa da comunidade de 2008 (B. Costa, 2012), atualizamos o mapeamento dos vestígios arqueológicos em superfície, inserindo sua localização

\footnotetext{
7 Pesquisa desenvolvida com apoio da Fundação de Amparo à Pesquisa do Estado de São Paulo (FAPESP) (processo 2014/01968-1), intitulada "Conservação arqueológica: uma reflexão a partir de estudos de caso no Brasil" (S. Lima, 2018).
} 
georreferenciada e os dados coletados em duas etapas de campo para monitoramento, em 2015 e 2016. Isso gerou um mapeamento cronológico, quantitativo e qualitativo, das vasilhas arqueológicas afloradas. Durante a primeira etapa, de 2017, além do monitoramento em superfície, também apresentamos os primeiros resultados obtidos com essa pesquisa para os representantes comunitários (Figura 7).

Ambas as etapas de campo tiveram diversas discussões entre as arqueólogas e os arqueólogos sobre a relevância e a pertinência de se preservar este material arqueológico in situ, tendo em vista que anualmente observamos que há perdas de material. Contudo, entre os diferentes olhares, houve uma constatação comum de que os dados coletados nos monitoramentos de 2015 e 2016 para a identificação e a descrição do material cerâmico em superfície também configuram um conjunto informacional significativo para o estudo arqueológico do material cerâmico, sendo passível sua associação e comparação com os dados de análise laboratorial do material arqueológico resgatado na etapa de escavação. De fato, apesar da perda anual de fragmentos removidos por chuva, erosão ou pelas pessoas, a metodologia de mapeamento e monitoramento in situ assegura a preservação da informação relacionada aos fragmentos conservados e/ou perdidos, sem que haja a remoção do material arqueológico de seu contexto e paisagem atual.

A elaboração dos mapas georreferenciados dos conjuntos cerâmicos, que evidencia a dinâmica em que novos conjuntos afloram e outros desaparecem, revela camadas entrelaçadas de vasilhas, o que permite um mapeamento cronológico dos processos de formação, transformação e movimentação dos afloramentos de vasos, indicando temporalidades diferentes de enterramento. Os mapas também corroboram a visualização dos conjuntos e sua localização em relação às áreas de circulação e moradia da comunidade, auxiliando a compreensão das diferentes intensidades dos processos de afloramento. Assim, os mapas compõem uma ferramenta fundamental para a discussão e a elaboração de estratégias de conservação pertinentes

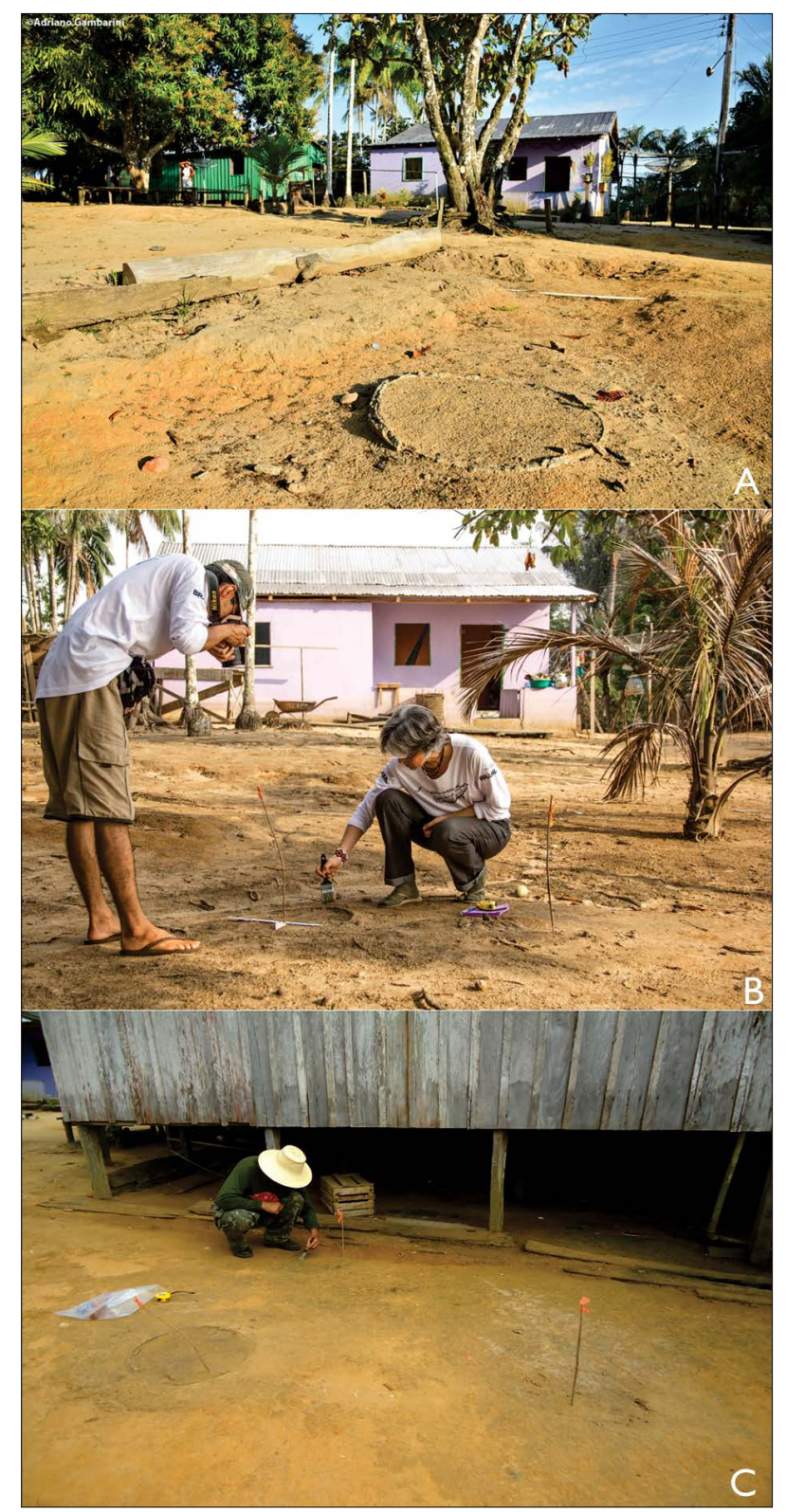

Figura 7. Aspectos gerais das atividades desenvolvidas em Boa Esperança: A) registro de vaso Caiambé aflorando na superfície da comunidade. Foto: Adriano Gambarini (2017); B e C) atividade de monitoramento das vasilhas. Fotos: Aline Fidelix (2015) e Márjorie Lima (2017).

à realidade da comunidade, do sítio arqueológico e da pesquisa.

A avaliação prévia do estado de conservação dos conjuntos de fragmentos e vasilhas afloradas, por meio

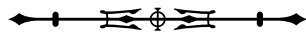


do monitoramento in situ, também tem sido fundamental para a discussão e o planejamento das atividades de intervenção do grupo. A situação dos conjuntos pode ser muito variada, com vasilhames localizados em áreas com maior risco de sofrer novas perdas, tanto por estarem em áreas de circulação de pessoas, como pelo risco de novas erosões no terreno, assim como conjuntos de vasilhas nas quais o nível de degradação torna as possibilidades de pesquisa mais limitadas.

Nas áreas da comunidade onde foram identificados conjuntos de cerâmica arqueológica, recentemente aflorados e em bom estado de conservação, o reenterramento tem sido pensado como uma estratégia passível de ser realizada em curto prazo e que tem uma ação que pode ter diferentes temporalidades. Segundo Pedeli e Pulga (2013, p. 113), "reburial should not be seen merely as a make shift solution. There are specific occasions. ... when this is the right decision given the conditions". O enterramento pode ser mantido por longo prazo para preservar essas vasilhas para ações futuras, ou a médio prazo, enquanto as pesquisas arqueológicas na região não podem ser retomadas de forma mais intensa. Esta é uma questão importante, pois influencia diretamente na escolha dos materiais utilizados para o fechamento destas áreas, de modo que o material arqueológico seja adequadamente conservado.

Visto que observamos no sítio tanto conjuntos de vasilhas e fragmentos que já foram completamente incorporados ao piso de terra e aos caminhos de circulação das pessoas como outros mais bem conservados, temos levado a proposta de reenterramento à comunidade Boa Esperança. Essa discussão também tem sido abordada como uma oportunidade de debate e compreensão da relação dos comunitários com o material arqueológico, na medida em que eles aceitem ou não este encaminhamento e interfiram na decisão de quais conjuntos devem ser reenterrados e quais devem ser mantidos expostos. Diferentes valores atribuídos ao material arqueológico influenciam na escolha de estratégias de conservação, pois enquanto algumas partes interessadas, como grupos de arqueólogos, podem representar obstáculos à escolha do reenterramento como estratégia, outras, como grupos indígenas, por exemplo, podem considerar essa ação sob uma ótica positiva (Demas, 2012, p. 447). Acreditamos que uma opção ou outra reafirmará as relações da comunidade com a paisagem, da qual as vasilhas são parte.

Apesar de durante reunião realizada com alguns líderes da comunidade em 2016, para apresentação da pesquisa, não termos conseguido desenvolver uma narrativa comum sobre as estratégias de conservação in situ, observamos no ano seguinte que algumas ações haviam sido realizadas com o intuito de conter os processos de erosão do terreno, como a colocação de contenções, plantio de gramíneas e o reenterramento de áreas erodidas que, concomitantemente, promovem a conservação das vasilhas antes expostas.

É comum, em sítios arqueológicos que se sobrepõem a comunidades atuais (ou vice-versa), encontrarmos áreas que são naturalmente ou artificialmente melhor preservadas. No caso de Boa Esperança, o campo de futebol está localizado sobre uma área de grande relevância para o estudo dos contextos de enterramento que envolvem recipientes de grande porte característicos deste sítio. Ao mesmo tempo, o campo é o 'cartão-postal' da comunidade, onde ocorrem diferentes campeonatos de futebol de Amanã. Entender a importância e a ocupação atual dos espaços da comunidade de forma associada aos estudos de diagnóstico do patrimônio arqueológico é uma ação fundamental para a preservação de áreas de relevância do sítio e deve ser algo incorporado às estratégias de conservação e gestão, que, nesse caso, têm nos levado a considerar a possibilidade de o campo de futebol ser a área de enterramento dos conjuntos de vasilhas mais conservados do sítio Boa Esperança.

Quando se fala em conservação in situ ou musealização de sítios arqueológicos (Sullivan \& Mackay, 2012; Bruno, 2014; Caple, 2016), é fundamental compreender que isto significa propor estratégias de média e longa duração, 
diferentemente das estratégias de escavação, que são, geralmente, de curto prazo. Neste processo, o envolvimento da comunidade local cria espaços para determinação conjunta daquilo que é culturalmente significativo e das ações para a preservação destes bens. Envolver na discussão sobre a gestão do patrimônio os diferentes grupos que interagem com o mesmo não impede a realização de tratamentos conservativos; ao contrário, impõe a necessidade de maior conhecimento dos materiais e técnicas para encontrar soluções criativas e adequadas às demandas locais (Jokilehto, 2012, p. 72).

No processo de tornar os mapas uma ferramenta acessível também à comunidade, em 2019, realizamos uma roda de conversa com jovens que participam de diferentes frentes comunitárias desde 2013. O objetivo foi buscar futuros agentes e interessados e interessadas na preservação arqueológica. Os jovens informaram que, a cada ano, tem aparecido mais cacos pela comunidade, assim como bocas de urnas. Disseram, ainda, que os elementos que mais os impactam são as chuvas, o regime das águas, a capinação e a varrição diária dos quintais. Indagamos se teriam interesse em participar de alguma ação voltada para o acompanhamento e o monitoramento das vasilhas. As respostas foram afirmativas, mas não foram formuladas ou indicadas estratégias a serem realizadas. Algumas das participantes já fazem parte de um projeto de monitoramento de peixes ${ }^{8}$. Em linha gerais, não notamos um entusiasmo específico com a possibilidade de trabalho com as urnas, mas uma vontade maior de estarem próximos das pesquisas do IDSM em geral.

No caso dos vasilhames que afloram, percebemos que, por um lado, escavar todos seria inviável, pelas questões já explicitadas anteriormente, por outro, não fazer nada pode significar que em algumas décadas os mesmos provavelmente não estarão mais na localidade. Ainda em 2019, em uma conversa com um dos líderes e fundadores da comunidade, foi relatado que esses potes, alguidares, cacos em geral que afloram, nascem da terra, são como o cimento da comunidade, pois impedem que as chuvas e as cheias lavem e levem a terra embora. Em áreas onde as famílias limparam o terreno, por uma questão estética, segundo a liderança, a terra está afundando. Ou seja, esses objetos do passado, que ajudam arqueólogos e arqueólogas a compreenderem os processos de mudança e continuidade, ao longo do tempo, são percebidos como o alicerce real e simbólico dessa comunidade. Para a prática arqueológica, o diálogo e o intercâmbio de conhecimentos - sejam científicos ou tradicionais - são o caminho para encontrar soluções conjuntas que atendam às demandas da preservação do patrimônio e da comunidade.

\section{BALANÇO DA REDE: CONSIDERAÇÕES FINAIS}

Enquanto profissionais que atuam com o tema do patrimônio arqueológico, entendemos que só é possível garantir sua conservação e gestão quando a visão de patrimônio é diversa e compartilhada com as populações vivas e que lidam diariamente com ele. É necessário um olhar ético (cf. Meskell, 2009; Hodder, 2011) e engajado para a compreensão da criação e da reinvenção da vida e da cultura sobre ou próximo aos sítios arqueológicos, que considera as particularidades locais de cada lugar e de seus moradores e moradoras. Procuramos aqui enfatizar que, devido a seu caráter abrangente, patrimônio e sua gestão devam ser pensados por uma série de profissionais, especialistas, agentes e grupos que se reconheçam nele, por meio de seu uso ou mesmo pelo estabelecimento de outras relações, como estranhamento e não pertencimento. Ao mesmo tempo, partilhamos da ideia de que esse patrimônio é significado e ressignificado constantemente na atualidade e que esse movimento de apropriação é parte de sua preservação.

\footnotetext{
8 Elas possuem um aplicativo no celular e toda semana precisam computar dados dos peixes pescados pelos comunitários, como tamanho, espécie e peso. Comentaram que é algo super fácil de fazer e que gostam muito do trabalho, sobretudo porque todo sábado vão à casa do Baré se conectar à internet para passar as informações à pesquisadora.
} 
Embora a reflexão aqui apresentada não tenha buscado resolver a problemática da preservação dos sítios e do patrimônio arqueológico na Amazônia, os caminhos percorridos pelo nosso grupo de pesquisa podem elucidar e direcionar algumas rotas possíveis para o futuro. Após dezenove anos da presença de arqueólogos e arqueólogas na comunidade Boa Esperança, em alguns momentos mais presentes e em outros menos, podemos sinalizar que, a partir de um trabalho interdisciplinar de pesquisa e sensível aos anseios comunitários, alguns caminhos apresentam resultados positivos para a preservação participativa deste sítio arqueológico.

A compreensão da noção de preservação do patrimônio, nesse caso, se estabelece como um conjunto de ações integradas, que caminha em sua gestação para o envolvimento de diferentes agentes, com suas epistemes e visões. Idealiza-se que estes estejam envolvidos em todas atividades de pesquisa, conservação, extroversão, entre outras frentes que caracterizem uma gestão sustentável do patrimônio arqueológico. O que tem guiado essas práticas é a importância dos bens arqueológicos às pessoas que convivem diariamente com eles. Embora cientes de que nossas ações ainda estejam em fase de amadurecimento, também vemos a necessidade de novos mecanismos por parte da legislação que abarquem ações sensíveis à tal lógica.

Através da avaliação de ações-piloto - como o monitoramento dos afloramentos arqueológicos, o processo de definição de áreas de relevância e impacto no sítio/comunidade ou a tomada conjunta da decisão de aterrar partes do sítio em áreas de maior deterioração -, temos buscado desenvolver mecanismos de diálogo mais sistemáticos e contínuos.

A revisão e a reflexão sobre nossas práticas têm gerado iniciativas originais e abertas a outros anseios e desejos do grupo, como a consolidação do grupo de jovens para o monitoramento, acompanhamento do afloramento de vasilhames e coleta de dados in situ sobre os mesmos, uma atividade ainda em desenvolvimento; a continuidade do trabalho com professores, professoras e estudantes para o mapeamento de outras noções patrimoniais e para a formação crítica em torno das coisas arqueológicas; a continuidade das pesquisas arqueológicas com a colaboraçãa dos comunitários; e, finalmente, a consolidação do turismo de base comunitária e/ou de produtos artesanais produzidos por essas comunidades, que se coloca como uma forma possível de reverberar a importância desses vasilhames para a comunidade, revertida diretamente em suporte financeiro.

Apesar desse cenário promissor, tais demandas se complexificam atualmente, com a falta de apoio e financiamento para pesquisa no país, assim como com os ataques em torno da ciência e do seu papel na vida contemporânea'. Pesquisar sempre foi um grande desafio em diferentes instâncias, sendo ainda maior em trabalhos que envolvam várias comunidades e pessoas, pois exige um exercício de escuta e envolvimento de diferentes agentes para a tomada de decisões.

Ao mesmo tempo que a escavação do sítio arqueológico gera anseios para o pesquisador ou a pesquisadora, e sua pesquisa, ela cria expectativas para a comunidade, portanto é necessário cuidado e responsabilidade durante nossa passagem por elas que, após nossa partida, continuam suas vidas. Podemos considerar que nossa atuação também interfere na dinâmica de formação do registro arqueológico, na medida em que o sítio continua sendo formado mesmo nos dias de hoje. O mesmo ocorreu no passado, com a transformação provocada pelos produtores da cerâmica polícroma, reconhecida na fase Tefé, cujas dinâmicas alteraram a ocupação anterior, formada pela fase Caiambé, que, por sua vez, transformaram a ocupação

9 Durante a escrita e revisão deste artigo, enfrentamos também o ataque virulento da Covid-19, o que provocará mudanças em todas as nossas práticas em dimensões mundiais e que não foram consideradas aqui. 
formada pelas cerâmicas Pocó, e assim por diante. $\bigcirc$ aprimoramento de metodologias de monitoramento dos sítios arqueológicos, para avaliar seus processos tafonômicos e mapear a formação desses palimpsestos, poderá também ajudar futuras pesquisas a entenderem o que está sendo escavado e a estruturarem ações de gestão do patrimônio, como a musealização e a conservação in situ de sítios arqueológicos.

Por isso, apontamos que esse desafio é uma rede de ações imbricadas, considerando atores com diferentes perspectivas em situações cujas peculiaridades exigem pensar novas possibilidades. A arqueologia, que tem sua história marcada pela interdisciplinaridade, precisa ainda aprender a envolver em sua prática outros agentes, incorporando diferentes visões, especialmente com distintos conhecimentos, científicos e tradicionais, de forma generosa e aberta. Consideramos que, em toda pesquisa atuante em áreas de comunidades, independentemente do enfoque do pesquisador ou da pesquisadora, são cruciais o diálogo e o exercício público de abrir seu trabalho às pessoas do local, assim como discutir suas implicações para as mesmas. Certamente, profissionais voltados para a chamada extroversão arqueológica são essenciais em todos os projetos de pesquisa, mas isso não deve eximir todos/ as envolvidos/as com o caráter social de seus trabalhos. Por outro lado, essas ações precisam superar o propósito de conscientizar as pessoas para o patrimônio ou de tentar sensibilizar as comunidades para a importância do que fazemos, com o intuito de obter autorização para a realização das pesquisas e para a apaziguação dos conflitos. Ao contrário, deve-se direcionar as discussões para fomentar uma abordagem crítica, que envolve as políticas do passado, com a desestabilização de interpretações dominantes (cf. Matsuda, 2016).

Em última instância, tais práticas são também um resgate da arqueologia como ciência social, que não deixa de ser histórica, visto que deve estar atenta às dinâmicas de mudança e continuidade que ocorrem na média e longa duração, cujas implicações se sentem no presente.

\section{AGRADECIMENTOS}

Esta pesquisa foi financiada pelo Ministério da Ciência, Tecnologia e Inovação (MCTI), por meio do Conselho Nacional de Desenvolvimento Científico e Tecnológico (CNPq) (300056/2017-6), pela Coordenação de Aperfeiçoamento de Pessoal de Nível Superior (CAPES), pela Fundação de Amparo à Pesquisa do Estado de São Paulo (FAPESP) (2014/01968-1) e pelo Instituto de Desenvolvimento Sustentável Mamirauá (IDSM). Agradecemos também às comunidades da Reserva de Desenvolvimento Sustentável Amanã, em particular às pessoas da comunidade Boa Esperança, enfocada neste texto.

\section{REFERÊNCIAS}

Appelbaum, B. (2009). Conservation treatment methodology. Butterworth-Heinemann.

Avrami, E., Manson, R., \& Torre, M. (Eds.). (2000). Values and Heritage conservation. Getty Foundation.

Avrami, E. (2009). Heritage, values, andsustainability. In A. Richmond \& A. Bracker (Eds.), Conservation: Principles, dilemmas and uncomfortable truths (pp. 184-196). Butterworth-Heinemann.

Bezerra, M. (2011). "As moedas dos índios": um estudo de caso sobre os significados do patrimônio arqueológico para os moradores da Vila de Joanes, ilha de Marajó, Brasil. Boletim do Museu Paraense Emílio Goeldi. Ciências Humanas, 6(1), 57-70. https:// dx.doi.org/10.1590/S1981-81222011000100005

Bezerra, M. (2013). Os sentidos contemporâneos das coisas do passado: reflexões a partir da Amazônia. Revista Arqueologia Pública, 7(1), 107-122.

Bezerra, M. (2017). Teto e afeto: sobre as pessoas, as coisas e a arqueologia na Amazônia. GKNoronha.

Bezerra, M. (2018). Com os cacos no bolso: O colecionismo de artefatos arqueológicos na Amazônia brasileira. Revista do Patrimônio Histórico e Artístico Nacional, (38), 85-99.

Bruno, M. C. O. (2014). Musealização da Arqueologia. Revista de Arqueologia, 27(1), 5-15.

Cabral, M. P. (2014). E se todos fossem arqueólogos? Experiências na Terra Indígena Wajãpi. Anuário Antropológico, 39(2), 115-132. https://doi.org/10.4000/aa.1269

Cabral, M. P. (2016). Entre passado e presente: arqueologia e coletivos humanos na Amazônia. Teoria \& Sociedade, 24(2), 76-91. 
Cabral, M. P., Pereira, D., \& Bezerra, M. (2018). Patrimônio arqueológico da Amazônia: a pesquisa, a gestão e as pessoas. Revista do Patrimônio Histórico e Artístico Nacional, 38, 247-268.

Caple, C. (Org.). (2016). Preservation of archaeological remains in situ: A reader. Routledge.

Carneiro, C. G. (2009). Ações educacionais no contexto da arqueologia preventiva: uma proposta para a Amazônia Tese de doutorado, Museu de Arqueologia e Etnologia, Universidade de São Paulo].

Cassino, M. F., Franco, C., Freire, G., Coelho, S., Lima, M., \& Tamanaha, E. K. (2018, agosto). Paisagens culturais da Reserva de Desenvolvimento Sustentável Amanã: identificação de florestas úteis na região do sítio arqueológico Boa Esperança, Amazonas, Brasil. Anais do XVI Congresso da Sociedade Internacional de Etnobiologia, XII Simpósio Brasileiro de Etnobiologia e Etnoecologia. Belém.

Colwell-Chanthaphonh, C., \& Ferguson, T. J. (2008). Collaboration in Archaeological practice: engaging descendant communities. Altamira Press.

Colwell-Chanthaphonh, C., Ferguson, T. .., Lippert, D., McGuire, R. H., Nicholas, G. P., Watkins, J. E., \& Zimmerman, L. J. (2010). The premise and promise of indigenous archaeology. American Antiquity, 75(2), 228-238. https://doi.org/10.7183/0002-7316.75.2.228

Costa, C. A. S. (2019). Por políticas para a gestão e musealização do patrimônio arqueológico: uma escala de sentidos. Habitus, 17(1), 101-124.

Costa, B. L. (2012). Levantamento arqueológico na Reserva de Desenvolvimento Sustentável (RDS) Amanã: estado do Amazonas [Dissertação de mestrado, Museu de Arqueologia e Etnologia, Universidade de São Paulo].

Costa, B. L. S., Py-Daniel, A., Gomes, J., \& Neves, E. G. (2012). Urnas funerárias no Lago Amanã, Médio Solimões, Amazonas: contextos, gestos e processos de conservação. Amazônica: Revista de Antropologia, 4(1), 60-91. http://dx.doi.org/10.18542/ amazonica.v4i1.882

Costa Leite, L. F. S. (2014). Pedaços de pote, bonecos de barro e encantados em Laranjal do Maracá, Mazagão - Amapá: perspectivas para uma arqueologia pública na Amazônia [Dissertação de mestrado, Universidade Federal do Pará].

Cury, M. X. (2017). Circuitos museais para a visitação crítica: Descolonização e protagonismo indígena. Revista Iberoamericana de Turismo, 7(3), 87-113.

Decreto n. 19.021. (1998, agosto 4). Cria a Unidade de Conservação denominada Reserva de Desenvolvimento Sustentável Amanã - RDS, e dá outras providências. http:// meioambiente.am.gov.br/wp-content/uploads/2018/03/ Decreto-19.021 Cria\%C3\%A7\%C3\%A3o-da-RDSAman\%C3\%A3 04.08.1998.pdf
Demas, M. (2012). Site Unseen: The case for reburial of archaeological sites. In S. Sullivan \& R. Mackay (Orgs.), Archaeological sites: Conservation and management (pp. 436457). The Getty Conservation Institute.

Descola, P. (2016). Outras naturezas, outras culturas. Editora 34.

Engelstad, B. D. (2010). Curators, collections and Inuit communities: Case studies from the Arctic. In L. Broekhoven, C. Buifs \& P. Hovens (Eds.), Sharing know ledge and cultural heritage: First nations of the Americas. Studies in Collaboration with indigenous peoples from Greenland, North and South America (pp. 39-52). Sidestone Press.

Feriz, H. (1963). The ceramics of Tefé-Amanã: A Contribution to the archaeology of the Amazon. Revista Ethnos, 28(2-4), 147-176.

Ferreira, L. M. (2013). Essas coisas não the pertencem: relações entre legislação arqueológica, cultura material e comunidades. Revista de Arqueologia Pública, 7(1[7]), 87-106. https://doi. org/10.20396/rap.v7i1.8635673

Ferreira, L. G., \& Bezerra, M. (2013). O lugar do passado no presente: as narrativas dos Joanenses acerca de museu e patrimônio arqueológico, um estudo de caso na llha do Marajó, Pará In M. Granato \& T. Scheiner (Orgs.), Museologia, patrimônio, interculturalidade: museus inclusivos, desenvolvimento e diálogo intercultural (pp. 163-178). Museu de Astronomia e Ciências Afins.

Furquim, L. P. (2014). Análise laboratorial do material cerâmico do sítio São Miguel do Cacau e monitoramento dos sítios em área de comunidade no Lago Amanã - RDSA - AM. [Relatório científico inédito]. IDSM.

Gomes, J. (2015). Cronologia e mudança cultural na RDS Amanã (Amazonas): um estudo sobre a fase Caiambé da Tradição Borda Incisa [Dissertação de mestrado, Museu de Arqueologia e Etnologia, Universidade de São Paulo].

Gomes, J. (2016). Alteridades e paisagens na Comunidade Boa Esperança, RDS Amanã (AM). Teoria \& Sociedade, 24(2), 92-114.

Gomes, J., Costa e Santos, R. B., \& Costa, B. L. S. (2014). Arqueologia comunitária na reserva Amanã: história, alteridade e patrimônio arqueológico. Amazônica: Revista de Antropologia, 6(2), 385-417. http://dx.doi.org/10.18542/ amazonica.v6i2.1874

Hilbert, P. P. (1962, julho). New stratigraphic evidence of culture change on the Middle Amazon (Solimões). Akten des $34^{\circ}$ Internationalen Amerikanisten kongresses, Viena.

Hilbert, P. P. (1968). Archäologische untersuchungen am mittlern Amazonas. Dietrich Reimer Verlag.

Hodder, I. (2011). Is a shared past possible? The ethics and practice of Archaeology in the twenty-first century. In K. Okamura \& A Matsuda (Eds.), New Perspectives in Global Public Archaeology (pp. 19-28). Springer.

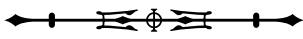


Jokilehto, J. (2012). Conservation concepts. In S. Sullivan \& R. Mackay (Orgs.), Archaeological sites: Conservation and management (pp. 71-81). The Getty Conservation Institute.

Liebmann, M., \& Rizvi, U. Z. (Eds.). (2008). Archaeology and the postcolonial critique. Altamira Press.

Lima, D. M. (1997). Eqüidade, desenvolvimento sustentável e conservação da biodiversidade. In E. Castro \& F. Pinton (Orgs.), Faces do trópico úmido: conceitos e questões sobre desenvolvimento e meio ambiente (Vol. 1, pp. 285-314). Cejup.

Lima, H. P., Moraes, B. M., \& Parente, M. T. V. (2013). 'Tráfico' de material arqueológico, turismo e comunidades ribeirinhas: Experiências de uma arqueologia participativa em Parintins, Amazonas. Revista de Arqueologia Pública, 7(2[8]), 61-77. https://doi.org/10.20396/rap.v7i2.8635692

Lima, H. P., Andrade, E. B., \& Silva, C. A. (2017). Gestão do patrimônio arqueológico na Amazônia: desafios da curadoria compartilhada na REDES do Tupé, Manaus, Amazonas. Revista de Arqueologia Pública, 11(2[19]), 114-137. https://doi. org/10.20396/rap.v11i2.8649677

Lima, H. P. (2019). Patrimônio para quem? Por uma arqueologia sensível. Habitus: Revista do Instituto Goiano de Pré-História e Antropologia, 17(1), 25-38. http://dx.doi.org/10.18224/hab. v17i1.7086

Lima, M. N. (2018). A cerâmica Pocó-Açutuba e seus processos correlatos na região Amazônica. Memorial de qualificação de doutorado [Relatório qualificação de doutorado inédito, Museu de Arqueologia e Etnologia, Universidade de São Paulo].

Lima, S. C. (2018). Conservação arqueológica: Uma reflexão a partir de estudos de caso no Brasil [Relatório científico de pós-doutorado inédito, Museu de Arqueologia e Etnologia, Universidade de São Paulo].

Machado, J. S. (2009). Arqueologia e história nas construções de continuidade na Amazônia. Boletim do Museu Paraense Emílio Goeldi. Ciências Humanas, 4(1), 57-70. https://doi.org/10.1590/ S1981-81222009000100006

Machado, J. S. (2013). História(s) indígena(s) e a prática arqueológica colaborativa. Revista de Arqueologia, 26(1), 72-85. https://doi. org/10.24885/sab.v26i1.369

Machado, J. S. (2014). Ilha Caviana: sobre as suas paisagens, tempos e transformações. Amazônica: Revista de Antropologia, 6(2), 283-313. http://dx.doi.org/10.18542/amazonica.v6i2.1870

Marçal, H., \& Macedo, R. (2017). From the periphery to the centre of decision: Community engagement and justice in conservation decision-making. In J. Bridgland (Ed.), ICOM-CC 18th Triennial Conference Preprints, Conhagen 4-8 September 2017. The International Council of Museums.
Matsuda, A. (2016). A consideration of public archaeology theories. Public Archaeology, 15(1), 40-49.

Meskell, L. (2009). Introduction: Cosmopolitan heritage ethics. In L. Meskell (Ed.), Cosmopolitan archaeologies (pp. 1-27). Duke University Press.

Muñoz Viñas, S. (2005). Contemporary Theory of conservation. Butterworth-Heinemann.

Nascimento, A. C. (Org.). (2020). Plano de Gestão da Reserva de Desenvolvimento Sustentável Amanã (Série Técnica Planos de Gestão). SEMA.

Pedeli, C., \& Pulga, S. (2013). Conservation practices on archaeological excavations: Principles and methods. Getty Publications.

Peralta, N. (2013, outubro). 'Guardar é para tirar depois': disputas territoriais e conceituais no Lago Mamirauá, AM. 37 Encontro Anual da ANPOCS, São Paulo.

Pereira, D. (2019). O 'roubo das urnas': a relação do patrimônio arqueológico salvaguardado e os coletivos humanos. Habitus, 17(1), 39-52. http://dx.doi.org/10.18224/hab.v17i1.7112

Roca, A. (2015). Acerca dos processos de indigenização dos museus: Uma análise comparativa. Mana, 21(1), 123-156. http://dx.doi. org/10.1590/0104-93132015v21n1p123

Rocha, B., Beletti, J., Py-Daniel, A., Moraes, C. P., \& Oliveira, V. H. (2014). Na margem e à margem: arqueologia amazônica em territórios tradicionalmente ocupados. Amazônica: Revista de Antropologia, 6(2), 358-384. http://dx.doi.org/10.18542/ amazonica.v6i2.1873

Sant'Anna, M. (2015). Preservação como prática: Sujeitos, objetos, concepções e instrumentos. In M. B. Rezende, B. Grieco, L. Teixeira \& A. Thompson (Orgs.), Dicionário IPHAN de Patrimônio Cultural (Vol. 1, pp. 245-279). IPHAN.

Shepard, G. (2001). Relatório preliminar sobre sítio arqueológico e cemitério indígena na Reserva Amanã. $1^{\text {a }}$ Superintendência do IPHAN.

Silva, F. A., Bespalez, E., \& Stuchi, F. F. (2011). Arqueologia colaborativa na Amazônia: Terra Indígena Kuatinemu, rio Xingu, Pará. Amazônica: Revista de Antropologia, 3(1), 32-59. http://dx.doi. org/10.18542/amazonica.v3i1.629

Silva, F. A. (2013). Território, lugares e memória dos Asurini do Xingu. Revista de Arqueologia da Sociedade de Arqueologia Brasileira, 26(1), 28-41. https://doi.org/10.24885/sab.v26i1.366

Silva, F. A. (2014). El pasado en el presente de los Asurini do Xingu: narrativas arqueológicas y narrativas indígenas. In M. C. Rivolta, M. Montenegro, L. M. Ferreira \&J. Nastri (Eds.), Multivocalidad y activaciones patrimoniales en arqueología: perspectivas desde Sudamérica (pp. 35-59). Editora de la UBA. 
Silva, F. A., \& Lima, S. C. (2015). Etnoarqueologia, conservação arqueológica e a compreensão dos processos de formação do registro arqueológico na Amazônia: a cerâmica arqueológica dos Asurini do Xingu, Pará. Revista de Arqueologia da Sociedade de Arqueologia Brasileira, 28(1), 123-142.

Silva, M. A. (2015). Memórias e histórias no sudoeste amazônico: o Museu Regional de Arqueologia de Rondônia [Dissertação de mestrado, Museu de Arqueologia e Etnologia, Universidade de São Paulo, São Paulo].
Silva, M. A. (2019). Entre tempos, entre lagos: etnografia arqueológica do advento do patrimônio na Reserva de Desenvolvimento Sustentável Amanã e na Floresta Nacional de Tefé - Amazonas [Memorial de qualificação de doutorado inédito, Museu de Arqueologia e Etnologia, Universidade de São Paulo, São Paulo].

Sullivan, S., \& Mackay, R. (Orgs.). (2012). Archaeological sites: Conservation and management. The Getty Conservation Institute.

\section{CONTRIBUIÇÃO DOS AUTORES}

M. Lima contribuiu com conceituação, curadoria de dados, aquisição de financiamento, investigação, metodologia, recursos, supervisão e escrita (rascunho original, revisão e edição); M. A. Silva com conceituação, aquisição de financiamento, investigação, metodologia, recursos, supervisão e escrita (rascunho original, revisão e edição); S. C. Lima com conceituação, curadoria de dados, aquisição de financiamento, investigação, metodologia, recursos, supervisão e escrita (rascunho original, revisão e edição); M. F. Cassino com conceituação, aquisição de financiamento, investigação, recursos e escrita (rascunho original, revisão e edição); e E. Tamanaha com conceituação, investigação, metodologia e escrita (rascunho original, revisão e edição). 